THURSDAY, MAY 9, 1872

\section{MENTAL DARKNESS IN HIGH PLACES}

$W^{\mathrm{E}}$ have long ago been told in the most forcible language and by the highest authority what will be the fate of a people whose leaders are blind; and the same authority has likewise informed us that the worst possible form of darkness is that in which we think we see. To have a one-sided, a short-sighted, or a distorted view of any principle or policy is frequently worse than not to see it at all, more especially in those who claim to wield the national power or to direct the national will. To have a short-sighted steersman is very bad, especially if the navigation be dangerous; but what must be the fate of the vessel if her steersman and look-out are both equally short-sighted ?

It is at the present moment a point of vital importance that our leaders should be well informed as to the true nature of the claims advanced by Science for a better recognition by the Government of this country. Yet we question very much whether the leaders of Government have a just conception as to what is demanded by men of science, and why it is demanded, nor do we think that some of our leading journals are much better informed.

We quote the following extract from the Times of April 26, referring to a speech made by Mr. Gladstone at the annual banquet of the Civil Engineers :-

"'A fair field and no favour" is the maxim of English administration. A field so fair, so extensive, and so promising, that all industry may find its place, and such an absence of favour that one as well as another may hope for success. If under such conditions of Government the State 'does nothing for Science,' it cannot be helped, nor need it be much lamented, considering how very little Science stands in need of the aid."

We will do Mr. Gladstone and the Times the justice to own that these sentiments embody much that is true. To be meddling and muddling in private concerns is certainly not the province of any Government; and some think that the present Government were wrong when they undertook the management of the telegraphs.

The State should neither on the one hand attempt too much, nor on the other hand should it neglect to perform its obvious duties. What, then, are the principles which should guide a conscientious and intelligent Government as to its action in such matters? There can, we think, be no doubt as to these principles. If a certain course of procedure be for the obvious benefit of the whole people, and if its accomplishment be beyond the power of private associations, but not beyond that of Government, then surely it ought to be undertaken.

Let us test the truth of this maxim by one or two illustrations. It is for the obvious benefit of this country that it should have good steam communication with the continent of Europe and with America. Nevertheless our steam packets ought certainly to remain as they are, in the hands of private companies. Natural laws may here be left to themselves, and they will doubtless work in such a manner that the companies will on the one hand receive a handsome profit, while the public will on the other hand be supplied with efficient steam communication.
Again, it is of great importance that the country should be well furnished with animal food, and here, as before the task of supplying it may with advantage be left to private enterprise.

But in connection with this supply, we come to a case in which Government have very properly interfered. It is very important that the meat should be good and wholesome, and that diseased cattle should not be imported. On the other hand the people themselves, apart from Government, have no power of stopping the importation of such cattle, and therefore Government have very properly come forward and lent their aid in securing to the people a thoroughly wholesome supply of animal food.

It will at once be seen from these and similar instances, that legislative interference is uncalled for wherever natural laws are at work to perform the required objects.

Such natural laws are in operation in all, or nearly all, of the arts and industries of life. To meddle with carpenters, or bricklayers, or shoemakers, is entirely beyond the province of Government. If a man has a genius for improving shoes, he must not expect Government to start him in business; but he must look around for the cooperation of a capitalist; in fact, he must carry his genius to market and dispose of it to the highest bidder.

But what if the man have a genius for discovering natural laws? Will Mr. Gladstone or the Times be good enough to indicate the whereabouts of the market in which his genius will be rewarded? We have just been told that it is not at the Treasury; well, but where is it? Or will they tell us that such a discovery will never be of any practical advantage? Hardly so; the time for saying such things is past. It will in all probability be of immense importance to all industries, and they will all derive much profit in consequence of this man's discovery ; yet he himself will derive none.

But we need not here attempt to prove that the advancement of Science is a question of national importance. This has been already demonstrated very conclusively by $\mathrm{Col}$. Strange and others who have recently devoted much attention to the subject. We pass on to consider whether its advancement can be undertaken by private bodies, such as the Royal Society or the British Association.

The recent actions of these bodies speak for themselves. The former has just discontinued a series of sun observations taken under its superintendence; while the latter has given up the maintenance of the Kew Observatoryboth on the plea of want of funds. Again, the maintenance of meteorological observatories has already been undertaken by Government as a thing beyond the means of private individuals.

In all directions the spread of Science is cramped by this want of money; to illustrate which we shall conclude by giving a short account of the recent attempt made by the British Association to establish a series of electrical standards on a scientific basis. One of the most important, and at the same time most difficult, determinations was that of the unit of resistance. In order to establish this unit upon the principles proposed by Weber and Thomson, it was necessary to associate together in an experimental investigation a scientific electrician, a mathematician, a metallurgist, and the director of a magnetic observatory. It was necessary first of all to determine the best kind of wire in which to embody the 
standard, and this required numerous experiments by a metallurgist; it was necessary to know what changes took place in the magnetism of the earth during the experiments, and this required the attendance of the director of a magnetical observatory ; a scientific electrician presided over the experiments, and associated himself with a mathematician who was well versed in the theory of electricity. The unit of resistance thus determined by the British Association has now been universally adopted by practical engineers; men of science have laboured, and the Postmaster-General has quietly entered into the fruits of their labour; but the experiments in connection with other units are not yet finished; in fact such researches, requiring as they do great skill and time for their accomplishment, must necessarily hang fire if the men who can perform them do not receive some support which will enable them to devote their best energies to the conduct of these and similar experiments.

We have now said enough to establish our point that the extension of Science is of national importance, and that in its present state this extension is beyond the means of private individuals, but not beyond the means of the State. Before concluding, we ought to mention (more especially since it cannot be gathered from the Times report) that one of our most distinguished men of science, Dr. Joule, was present at the banquet to which we have alluded, and in returning thanks for Science took the opportunity of stating that he trusted Science would soon obtain that recognition which it imperatively required. If men of science will be true to themselves and to their noble cause, we feel confident that sooner or later they will prevail.

\section{HOOD ON BONE-SETTING}

On Bonc-Setting. By Wharton P. Hood, M.D., M.R.C.S. (Macmillan and Co., r87 I.)

T $\mathrm{O}$ any but the professional reader this title is not attractive ; and yet we are greatly mistaken if the book itself does not prove to the full as attractive and as lastingly interesting to the intelligent non-professional as to the professional reader; and this, not because the subject is lowered to the level of general comprehension, or written in what is called a "popular" style, but simply because the subject itself is of such wide and varied interest, and its whole treatment in the present little volume is so frank, so clear, and so convincing.

It will be asked, What is bone-setting, who are the bone-setters, and who are their patients? And it will be readily answered, Why, of course, bone-setting is the art of setting bones that have been broken, or joints that have been dislocated, and this is done, doubtless, by surgeons; and equally doubtless and of course, their patients are persons whose bones are fractured, or whose joints are dislocated-

There needs no ghost come from the grave to tell us that.

Perhaps not, but the answer is quite wrong for all that ; quite the reverse indeed of what is actually the case, for bone-setting is not the art of re-setting broken bones or dislocated joints ; bone-setters are not surgeons, or regular practitioners in any sense of the title ; and their patients, even when they have suffered injury to joint or bone, have been pronounced by the regular practitioner cured before seeking the hclp of the bone-setter.
Having stated this triple paradox, let us hear what Dr. Hood has to say in explanation.

"A healthy man sustains a fracture of one or both bones of the fore-arm, and applies at a hospital, where splints are adapted in the usual way. He is made an out-patient, and the splints are occasionally taken off and replaced. After the lapse of a certain number of weeks the fracture becomes firmly united, the splints are laid aside, and the man is discharged as cured. He is still unable to use either his hand or his fore-arm, but is assured that his difficulty arises only from the stiffness incidental to long rest of them, and that it will soon disappear. Instead of disappearing, however, it rather increases, and in due time he seeks the aid of a bone-setter. - . The bone-setter would then by a rapid manipulation, hereafter to be described, at once overcome the stiffness of the fingers, and enable the patient to move them to and fro. The instant benefit received would dispel all scruples about submitting the wrist and the elbow to manipulation, and these would be set free in their turn. The man would go away easily flexing and extending his lately rigid joints, \&c."

Now what was the cause of stiffness in the foregoing typical case? What was the nature of the impediment to normal movement, ignored by the surgeon and overcome by the bone-setter? The impediment above indicated, it is argued, might arise from articular inflammation, producing adhesions between surfaces "resting in apposition," and that such adhesions, if so placed as to restrain movement, will cause pain and irritation whenever they are rendered tense; and, moreover, that inflammation sufficient to produce these adhesions may be insi:s ously set up in a joint by extension from neighbouring structures-as in the above-recited case. Again, it is argued, "possibly in some cases, the proper ligaments may become contracted or rigid, or adherent to neighbouring parts ; in others, internal or external adventitious fibrous bands may be formed; in others, muscles may have undergone shortening. Again, effusion may have become soliditied, and thus movement be impaired, as if by a state ot things analogous to a rusty hinge." And further on: "If we consider the amount and character of the effusion which takes place after some sprains and injuries, in some gouty and rheumatic affections, and in some cases of suppuration occurring in bursa, or beneath deep fascia, we cannot dolibt that such effusion may easily assume forms in which it will tie down muscles, tendons, or even articular nerves themselves."

The art of bone-setting, then, is the art of overcoming these impediments in joints, these conditions of arrested or impaired freedom which not unfrequently supervene on the curative processes of treatment in use by surgeons in cases of fracture or dislocation; or which may arise from, and be observed only after the subsidence of, active rheumatism, gout, ganglionic swellings, or other local affections ; and this brings us to the question, How is it done? how are these stiffened joints set free? how are these impediments to healthy action overcome? The answer of the regular practitioner is that which has been already quoted, namely, to rest it-advice which usually entails a distressing failure ; the answer of the irregular practitioner, i.e., the bone-setter, is precisely the opposite, namely, that freedom can only be restored to the stiffened joint by movement, by manipulation, and manipulation too of the most formidable kind, nothing less than suddenly and forcibly rupturing, tearing asunder, the adhesions formed 